\title{
Virtual and Augmented Reality in Spatial Visualization
}

\author{
Dennis Edler ${ }^{1}\left[\right.$ (1) Thomas P. Kersten ${ }^{2}$ (1)
}

Published online: 30 November 2021

(C) The Author(s) 2021

In recent years, the potentials of virtual and augmented reality (VR/AR) have attracted a growing interdisciplinary community of international researchers and users. Numerous projects exist in research fields, such as cultural heritage and architecture, urban and regional planning, construction planning and product development, training simulations (e.g., rescue services) and education. While AR is commonly understood as an extension of observable reality through the combination of reality and virtuality, VR is associated with the visualization and simultaneous real-time perception of reality and its physical characteristics within interactive virtual environments.

In the VR and AR community, the year 2015 is often associated with the free release of the Unreal Engine, a formerly proprietary game engine used in the computer gaming industry. The free availability of established game engines has given a powerful impulse to modern visualization disciplines. As game engines are bound to an understanding of 'world-building', the reference to geographic space (concerning virtual representations of real physical or fictional environments) is inherent. Therefore, it is not surprising that there is a vivid and steadily ongoing international research debate on how to use the potentials of virtual environments and augmented spaces for a user-oriented cartography and spatial visualization. Moreover, these virtual or augmented spatial media can serve as 'virtual labs' which are used for empirical research with standardized procedures and for visual analytics.

The possibilities of game engines further benefit from the availability and compatibility of mass media hardware

Dennis Edler

Dennis.Edler@ruhr-uni-bochum.de

Thomas P. Kersten

Thomas.Kersten@hcu-hamburg.de

1 Ruhr-Universität Bochum, Geographisches Institut, AG Geomatik, Universitätsstr. 150, 44801 Bochum, Germany

2 Labor für Photogrammetrie and Laserscanning, HafenCity Universität Hamburg, Henning-Voscherau-Platz 1, 20457 Hamburg, Germany systems, such as head-mounted displays (HMDs) or smartphones. These technical devices strengthen the feeling of immersion into these solely virtual or virtually extended environments, which leads to new capabilities of experiencing a realistic $3 \mathrm{D}$ environment from an ego-perspective in a simulated $1 / 1$ scale. The demand for a high realism also bears potentials for the integration and transformation of traditional and new geospatial data resources, such as remotely sensed data, 3D city models as well as thematic assets created by professionals or 'home brewers'.

This special issue is a collection of current research projects showing the potentials of AR and VR, with a specific focus on the visualization of spatial information. It is part of the work of the DGfK/DGPF joint commission on "Virtual and Augmented Reality" (founded in 2019):

Ian Lochhead and Nick Hedley (Burnaby, BC, Canada) developed a prototype of an immersive virtual GIScience data visualization space called "IVEVA". In their article, they present a collection of 3D data-driven geovisualization case studies based on the IVEVA VR interface. Their examples and results show the potentials of VR interfaces for immersive visual analytics.

Thomas P. Kersten, Daniel Drenkhan and Simon Deggim (Hamburg) address the topic of performance for smooth real-time VR visualization. Using a case example in the field of cultural heritage, the Fortress Al Zubarah in Qatar, they conduct and discuss a performance analysis of real-time visualization in VR.

Claudia Lindner, Annette Ortwein, Kilian Staar and Andreas Rienow (Bochum) provide insights on how VR and AR techniques serve to visualize extra-terrestrial data. These VR and AR applications are developed for educational purposes and deal with case examples on Mars.

Tymoteusz Horbiński and Krzysztof Zagata (Poznań, Poland) address the meaning of cartographic symbols used in the Video Valheim. The set of symbols used in this game adapt the historical context of the Viking era. Using an online survey, the authors empirically investigate interpretations of the cartographic symbols. 
Frank Dickmann, Julian Keil, Paula L. Dickmann and Dennis Edler (Bochum) give an overview of important visualization properties of current AR techniques. Their potentials and limitations for cartographic applications are discussed.

Olaf Kühne (Tübingen) links current developments of VR and VA with cartographic theory formation. Based on Karl Popper's theory of three worlds, he discusses the relation of a framework of neopragmatic exploration with VR and AR visualizations.

We hope you enjoy reading the articles of this special issue, and we are looking forward to meeting all VR/AR interested people at the next DGfK and DGPF events and conferences.

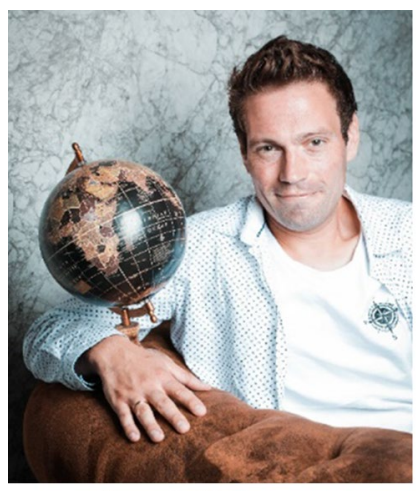

Dennis Edler

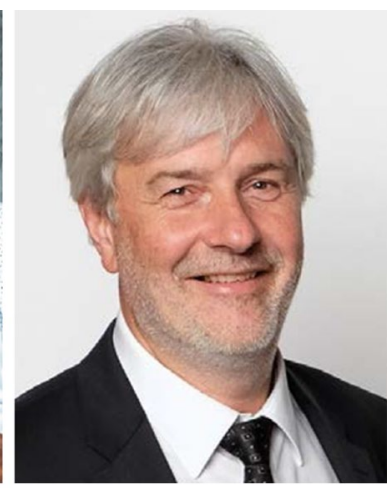

Thomas P. Kersten
Funding Open Access funding enabled and organized by Projekt DEAL.

Open Access This article is licensed under a Creative Commons Attribution 4.0 International License, which permits use, sharing, adaptation, distribution and reproduction in any medium or format, as long as you give appropriate credit to the original author(s) and the source, provide a link to the Creative Commons licence, and indicate if changes were made. The images or other third party material in this article are included in the article's Creative Commons licence, unless indicated otherwise in a credit line to the material. If material is not included in the article's Creative Commons licence and your intended use is not permitted by statutory regulation or exceeds the permitted use, you will need to obtain permission directly from the copyright holder. To view a copy of this licence, visit http://creativecommons.org/licenses/by/4.0/. 